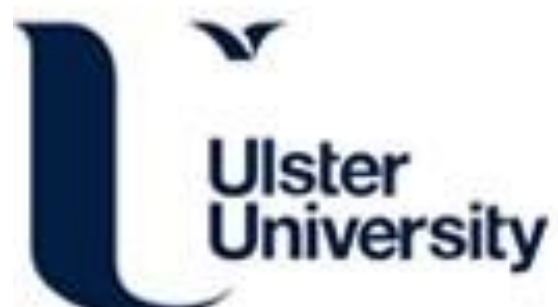

\section{Electronic structures and bonding properties of chlorine-treated nitrogenated carbon nanotubes: X-ray absorption and scanning photoelectron microscopy studies}

Ray, SC., Pao, CW., Tsai, HM., Chiou, JW., Pong, WF., Chen, CW., Tsai, MH., Papakonstantinou, P., Chen, LC., Chen, KH., \& Graham, WG. (2007). Electronic structures and bonding properties of chlorine-treated nitrogenated carbon nanotubes: X-ray absorption and scanning photoelectron microscopy studies. Applied Physics Letters, 90(19), 192107. https://doi.org/10.1063/1.2737392

Link to publication record in Ulster University Research Portal

Published in:

Applied Physics Letters

Publication Status:

Published (in print/issue): 08/05/2007

DOI:

10.1063/1.2737392

Document Version

Publisher's PDF, also known as Version of record

\section{General rights}

Copyright for the publications made accessible via Ulster University's Research Portal is retained by the author(s) and / or other copyright owners and it is a condition of accessing these publications that users recognise and abide by the legal requirements associated with these rights.

\section{Take down policy}

The Research Portal is Ulster University's institutional repository that provides access to Ulster's research outputs. Every effort has been made to ensure that content in the Research Portal does not infringe any person's rights, or applicable UK laws. If you discover content in the Research Portal that you believe breaches copyright or violates any law, please contact pure-support@ulster.ac.uk. 


\title{
Electronic structures and bonding properties of chlorine-treated nitrogenated carbon nanotubes: X-ray absorption and scanning photoelectron microscopy studies
}

\author{
S. C. Ray, C. W. Pao, H. M. Tsai, J. W. Chiou, and W. F. Pong ${ }^{a)}$ \\ Department of Physics, Tamkang University, Tamsui 251, Taiwan \\ C. W. Chen \\ Department of Materials Science and Engineering, National Taiwan University, Taipei 106, Taiwan \\ M.-H. Tsai \\ Department of Physics, National Sun Yat-Sen University, Kaohsiung 804, Taiwan \\ P. Papakonstantinou \\ NRI, School of Electrical and Mechanical Engineering, University of Ulster at Jordanstown, Newtownabbey, \\ County Antrim BT37OQB, Northern Ireland, United Kingdom \\ L. C. Chen \\ Center for Condensed Matter Sciences, National Taiwan University, Taipei 106, Taiwan \\ K. H. Chen \\ Institute of Atomic and Molecular Sciences, Academia Sinica, Taipei 106, Taiwan
}

W. G. Graham

Department of Physics and Astronomy, Queens University of Belfast, Belfast, Antrim BT71NN, Northern Ireland, United Kingdom

(Received 8 February 2007; accepted 19 April 2007; published online 8 May 2007)

\begin{abstract}
The electronic and bonding properties of nitrogenated carbon nanotubes (N-CNTs) exposed to chlorine plasma were investigated using $\mathrm{C}$ and $\mathrm{N} K$-edge $\mathrm{x}$-ray absorption near-edge structure (XANES) and scanning photoelectron microscopy (SPEM). The $\mathrm{C}$ and $\mathrm{N} K$-edge XANES spectra of chlorine-treated N-CNTs consistently reveal the formation of pyridinelike N-CNTs by the observation of $1 s \rightarrow \pi^{*}\left(e_{2 u}\right)$ antibonding and $1 s \rightarrow \pi^{*}\left(b_{2 g}\right)$ bonding states. The valence-band photoemission spectra obtained from SPEM images indicate that chlorination of the nanotubes enhances the $\mathrm{C}-\mathrm{N}$ bonding. First-principles calculations of the partial densities of states in conjunction with $\mathrm{C} K$-edge XANES data identify the presence of $\mathrm{C}-\mathrm{Cl}$ bonding in chlorine treated N-CNTs. (C) 2007 American Institute of Physics. [DOI: 10.1063/1.2737392]
\end{abstract}

Carbon nanotubes (CNTs) have attracted extensive attention, partly owing to their favorable electronic properties. ${ }^{1}$ The doping of nitrogen impurities in CNTs was found to be a possible route to tune the band gap such that CNTs can be exploited to make various electronic devices. ${ }^{2}$ The fluorinated CNTs can be tuned from metal to semiconductor/ insulator with high resistivity at elevated temperatures. ${ }^{3}$ Fluorination can also improve the wetting of nanotubes in water by inducing a surface dipole layer on the nanotube wall. This effect may be useful in battery and supercapacitor applications. ${ }^{4}$ Iodine- and bromine-doped CNTs were found to enhance the electronic/electrical properties by increasing the density of free charge carriers. ${ }^{5}$ Therefore, it is interesting to understand the effect of chemical modification of CNTs using halogens (F, I, Br, and $\mathrm{Cl}$ ). Fluorine-, iodine-, and bromine-treated CNTs (Refs. 3-5) and CNT-based nanomaterials $^{6-8}$ have been investigated previously. The electronic and bonding properties of chlorine-treated nitrogenated carbon nanotubes (N-CNTs:Cl) have not been fully carried out. Here, the electronic structures and bonding properties of freshly prepared N-CNTs, which were further treated with chlorine plasma in an inductively coupled plasma system, have been studied using $\mathrm{x}$-ray absorption

\footnotetext{
a) Author to whom correspondence should be addressed: electronic mail:
} wfpong@mail.tku.edu.tw near-edge structure (XANES) and scanning photoelectron microscopy (SPEM).

The $\mathrm{C}$ and $\mathrm{N} K$-edge XANES, and SPEM measurements were performed at the National Synchrotron Radiation Research Center in Hsinchu, Taiwan. In the preparation of CNTs, the vertically oriented multiwall N-CNTs were initially synthesized by microwave-plasma-enhanced chemicalvapor deposition on silicon substrates precoated with an $e$-beam evaporated thin Fe catalytic layer. ${ }^{9}$ Then, the obtained N-CNTs were chlorinated in an inductively plasmacoupled reactor in flowing $\mathrm{Cl}$ gas at $5 \mathrm{sccm}$ for periods of 1 and $5 \mathrm{~min}$ [denoted as N-CNTs:Cl $(1 \mathrm{~min})$ and N-CNTs:Cl (5 min) later on].

Figure 1 displays C $K$-edge XANES spectra of N-CNTs with and without chlorine treatment and the highly oriented pyrolytic graphite (HOPG) as a reference. The feature with the maximum intensity at approximately $285.5 \mathrm{eV}$ for HOPG was attributed to the $\pi^{*}$ antibonding state originated from the out-of-plane bonds in the $s p^{2}$ bonding configuration. ${ }^{10}$ The positions of $\pi^{*}$ resonance feature in the C $(1 s)$ XANES spectra of N-CNTs and N-CNTs:Cl located at $\sim 286.4$ and $286.7 \mathrm{eV}$, respectively, which are shifted by $\sim 0.9 \mathrm{eV}$ for $\mathrm{N}-\mathrm{CNTs}$ and $1.2 \mathrm{eV}$ for N-CNTs:Cl with respect to that of HOPG $(285.5 \mathrm{eV})$, correspond to the $1 s \rightarrow \pi^{*}\left(e_{2 u}\right)$ transition as in the pyridinelike $s p^{2} \mathrm{C}-\mathrm{N}$ structure. ${ }^{11}$ Pyridine is also well known to have two unfilled $\pi^{*}$ orbitals (as in benzene) 


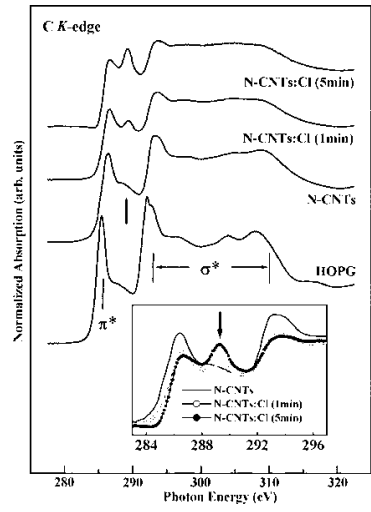

FIG. 1. C $K$-edge XANES spectra of unchlorinated/chlorinated N-CNTs and reference HOPG. The inset highlights the $\pi^{*}$ region.

with $e_{2 u}$ (an antibonding state whose wave functions are antisymmetric) and $b_{2 g}$ (a bonding state whose wave functions are symmetric) symmetry. ${ }^{11}$ The latter is observed at $\sim 289.2 \mathrm{eV}$ in the $\pi^{*}$ region for N-CNTs: $\mathrm{Cl}$, and its intensity increases with the Cl-treatment time. This feature is attributable to the transition of $1 s \rightarrow \pi^{*}\left(b_{2 g}\right)$ similar to that of the pyridine structure with the symmetric bonding state, ${ }^{11}$ and/or $\mathrm{C}-\mathrm{Cl}$ bonds, as observed by Unger et al. at $289.0 \mathrm{eV}$ in $\mathrm{X}$-ray photoelectron analysis of $\mathrm{Cl}$-functionalized multiwall CNTs. ${ }^{12}$ Previous works of carbon systems revealed a similar double feature in the $\mathrm{C}(1 s)$ XANES spectra. ${ }^{13}$ For N-CNTs, a small shoulder observed at $\sim 289 \mathrm{eV}$ (indicated by a vertical arrow) was attributed to the presence of interlayer graphite states, which was correlated with the calculated electronic state of dual-layer graphite sheets. ${ }^{14}$ In the $\sigma^{*}$ region, the centers of the maximum features of N-CNTs and N-CNTs:Cl appear at $\sim 293.2$ and $293.6 \mathrm{eV}$, respectively, similar to those of the pyridine structure. ${ }^{11}$ Interestingly, the intensities of $1 s \rightarrow \pi^{*}\left(e_{2 u}\right) \quad(286.4 / 286.7 \mathrm{eV})$ and $\sigma^{*}(293.2 / 293.6 \mathrm{eV})$ features decrease, while that of $1 s \rightarrow \pi^{*}\left(b_{2 g}\right)$ feature (indicated by the arrow) increases with the increase of $\mathrm{Cl}$ treatment time, as clearly shown in the inset of Fig. 1. This trend suggests the formation of a more symmetric bonding state in the N-CNTs than in the pyridine structure. To identify clearly these features, the $p$-projected conduction-band partial densities of states (PDOSs) of pure CNTs, N-CNTs, and N-CNTs: $\mathrm{Cl}$ are calculated using the CASTEP code, ${ }^{15}$ which is a plane-wave pseudopotential program based on the density functional theory and local density approximation, and are shown in Fig. 2. The benzene, pyridine, and pyridine- $\mathrm{Cl}$ cluster models are employed to represent local

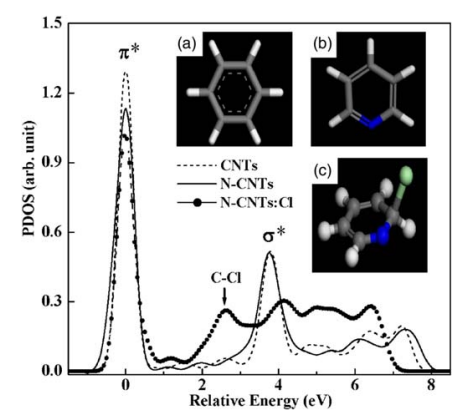

FIG. 2. (Color online) PDOSs of various CNTs. Insets (a), (b), and (c) show the cluster models, which represent the local bonding configurations of CNTs, N-CNTs, and N-CNTs:Cl, respectively. Blue- and light-green colored balls indicate $\mathrm{N}$ and $\mathrm{Cl}$ atoms, respectively. Downloaded 07 Jan 2010 to 193.61.144.141. Redistribution subject to AlP license or copyright; see http://apl.aip.org/apl/copyright.jsp The inset highlights the $\pi^{*}$ region.

bonding configurations of CNTs, N-CNTs, and N-CNTs:Cl, respectively. The hydrogen atoms in these models saturate the dangling bonds of carbon atoms, so that these carbon atoms mimic those in CNTs, N-CNTs, and N-CNTs:Cl. The insets (a)-(c) in Fig. 2 present the bonding configurations of these three CNTs; blue and green colors in the bonding structures indicate the attachment of $\mathrm{N}$ and $\mathrm{Cl}$ atoms in pure CNTs, respectively. Details of the calculations for the cluster models of these CNTs with various geometries can be found elsewhere. ${ }^{16}$ In Fig. 2, the feature located at $\sim 2.6 \mathrm{eV}$ between $\pi^{*}$ and $\sigma^{*}$ for the cluster model of pyridine-Cl may correspond to the extra feature indicated by the arrow between $\pi^{*}$ and $\sigma^{*}$ features in the inset of Fig. 1 and can be attributed to the $\mathrm{C}-\mathrm{Cl}$ bond.

Figure 3 displays the $\mathrm{N} K$-edge XANES spectra of the N-CNTs and N-CNTs:Cl samples. The two main features centered at $\sim 403.2$ and $\sim 409.5 \mathrm{eV}$ are associated with transitions into unoccupied $\pi^{*}$ and $\sigma^{*}$ orbitals, respectively. As stated above, the pyridine structure has two unfilled $\pi^{*}$ orbitals with $e_{2 u}$ and $b_{2 g}$ symmetries, which are typically observed in the $\mathrm{N} K$-edge XANES spectra at $\sim 400.0$ and $\sim 403.7 \mathrm{eV}$, respectively, for nitrogenated carbon films. ${ }^{11}$ The features in the $\mathrm{N} K$-edge XANES spectra in Fig. 3 are similar for all N-CNTs. The prominent feature centered at $\sim 403.2 \mathrm{eV}$ in the $\pi^{*}$ resonance has the $b_{2 g}$ symmetry of the pyridine structure. ${ }^{11}$ Jimènez et al. ${ }^{17}$ also observed this feature at $403.5 \mathrm{eV}$ for $s p^{2}$-hybridized nitrogenated carbon films, for which the $\pi^{*}$ region can be resolved into four peaks. The broad feature centered at $\sim 409.5 \mathrm{eV}$ in the $\sigma^{*}$ region is associated with the $\mathrm{C}-\mathrm{N}$ bond and is identical to that of the pyridine structure. ${ }^{11,17}$ The inset in Fig. 3 reveals that the intensity of the $\pi^{*}$ features in the $\mathrm{N} K$-edge XANES spectra decreases with the Cl-treatment time consistent with the trend of the $\mathrm{C} K$-edge XANES spectra shown in the inset of Fig. 1, which consistently indicate that $\mathrm{Cl}$ treatment increases the occupation of the $b_{2 g}$ symmetry states or enhances the pyridinelike $\mathrm{C}-\mathrm{N}$ bonding.

Figure 4 displays spatially resolved valence-band photoemission spectra of N-CNTs and N-CNTs:Cl with corresponding $\mathrm{C} 1 s$ SPEM cross-sectional images. The bright area in the SPEM image corresponds to the N-CNTs and N-CNTs:Cl with a maximum C $1 s$ intensity. The spectra presented in Fig. 4 exhibit photoelectron yields from the bright regions $\boldsymbol{S}_{0}$ (N-CNTs), $\boldsymbol{S}_{1}$ (1 min $\mathrm{Cl}$ treated), and $\boldsymbol{S}_{5}$ (5 min $\mathrm{Cl}$ treated), which correspond to the sidewalls of the respective N-CNTs, N-CNTs:Cl (1 min), and CNTs:Cl (5 min).
FIG. 3. N $K$-edge XANES spectra of unchlorinated/chlorinated N-CNTs. 


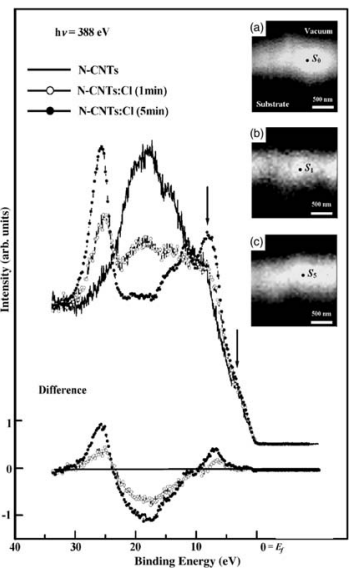

FIG. 4. Valence-band photoemission spectra obtained from selected brightspot $\boldsymbol{S}_{0}, \boldsymbol{S}_{1}$, and $\boldsymbol{S}_{5}$ of C $1 \mathrm{~s}$ SPEM cross-sectional images of unchlorinated/ chlorinated N-CNTs at the excitation photon energy of $388 \mathrm{eV}$. The inset shows difference between N-CNTs: $\mathrm{Cl}$ and $\mathrm{N}-\mathrm{CNTs}$ spectra.

The spectra contain two weak structures at binding energies of $\sim 3.5$ and $8.2 \mathrm{eV}$ (shown by down arrows) associated with the C $2 p \pi$ and $\sigma$ bonds, respectively. ${ }^{18-20}$ The spectra of $\mathrm{N}-\mathrm{CNTs}: \mathrm{Cl}(1 \mathrm{~min})$ and CNTs:Cl $(5 \mathrm{~min})$ show that chlorine treatment of N-CNTs broadens the feature of the $\sigma$ bond and increases its intensity. The change in the $\sigma$-bond feature may be associated with chlorine-derived $\sigma$ states and can be caused by the formation of $\mathrm{C}-\mathrm{Cl}$ and/or $\mathrm{N}-\mathrm{Cl}$ bonds. However, the physical origin of this feature remains uncertain. Features observed at $\sim 15 \mathrm{eV}$ (mixed $s$ and $p$ characters of the $\mathrm{C}-\mathrm{N}$ bond) and $\sim 19 \mathrm{eV}$ (C $2 s$ ) are typically observed in nitrogenated carbon films with a graphitic structure. ${ }^{21}$ The intensities of these two features $(\sim 15$ and $19 \mathrm{eV})$ decrease with the chlorine treatment, while the intensity of another new feature in the $24-30 \mathrm{eV}$ range (centered at $\sim 26 \mathrm{eV}$ ), which is attributable to $\mathrm{N} 2 s$ states, increases with the chlorine treatment. This result reflects the increase and decrease of the numbers of $\mathrm{C}-\mathrm{N}$ and $\mathrm{C}-\mathrm{C}$ bonds, respectively, and the formation of a pyridine structure in nitrogenated carbon films, as described by Bhattacharyya et al. for nitrogenated carbon films. ${ }^{21}$ The $\mathrm{N} 2 s$ peak is very prominent, despite the fact that the N/C at. \% ratio is only 0.033 (for N-CNTs) and 0.054 (for $\mathrm{N}-\mathrm{CNTs}: \mathrm{Cl}$ ), which may suggest that $\mathrm{N} 2 s$ orbital has a larger effective cross-section area or transition probability than those of $\mathrm{C}$ valence orbitals for the $388 \mathrm{eV}$ photon. This feature is observed in various nitrogen-based materials, and its intensity increases with the nitrogen concentration. ${ }^{22}$ The difference between N-CNTs: $\mathrm{Cl}$ and N-CNTs spectra, as shown in the lower inset of Fig. 4, illustrates the effect of the treatment of N-CNTs with chlorine. The difference spectra contain two positive features in the $\pi$ and $\sigma$ regions (within the range of $0-9 \mathrm{eV}$ ) and another feature (in the range of $24-30 \mathrm{eV}$ ) centered at $\sim 26 \mathrm{eV}$. A negative feature centered at $\sim 18 \mathrm{eV}$ is a signature of the decrease in the number of $\mathrm{C} 2 s$ bonds, which is consistent with an increase of the intensity of the feature at $\sim 26 \mathrm{eV}$ and the formation of the $\mathrm{C}-\mathrm{N}$ bond. It may also be associated with the formation of either $\mathrm{C}-\mathrm{Cl}$ and/or N-Cl bonds by the substitution of $\mathrm{C}-\mathrm{C}$ bonds.

The increase of the intensity of the feature between $\pi^{*}$ and $\sigma^{*}$ in the $\mathrm{C} K$-edge XANES spectra (at $\sim 289.2 \mathrm{eV}$ in the inset of Fig. 1 and the $\mathrm{C}-\mathrm{Cl}$ bond peak (at $\sim 2.6 \mathrm{eV}$ shown in
Fig. 2) in the calculated conduction-band PDOSs are a strong evidence of the contribution of $\mathrm{C}-\mathrm{Cl}$ bonds in N-CNTs:Cl. The decrease of the intensity of the $\pi^{*}$ feature (shown in the inset of Fig. 3) and the increase of the intensity of the feature at $\sim 289.2 \mathrm{eV}$ (shown in the inset of Fig. 1) with the increase of the Cl-treatment time in the $\mathrm{N} K$-edge and $\mathrm{C} K$-edge XANES spectra, respectively, indicate the formation of $s p^{2}$ $\mathrm{C}-\mathrm{N}$ bonded $\mathrm{N}-\mathrm{CNTs}$ with more symmetric pyridinelike structures. In the case of SPEM shown in Fig. 4, chlorine treatment of N-CNTs broadens the $p-\sigma$ bond associated with chlorine-derived $\sigma$ states and markedly increases the intensity of the new feature at $\sim 26 \mathrm{eV}$, which is attributable to $\mathrm{N}$ $2 s$ states. $^{22}$ This unusually sensitive $\mathrm{N}$ signal may indicate that $\mathrm{N}$ is on the surface. These observations in conjunction with the theoretical calculation suggest that the formation of pyridine, the increased symmetry of the N-CNTs states, and the possible formation of mixed $\mathrm{C}-\mathrm{Cl}, \mathrm{N}-\mathrm{Cl}$, and $s p^{2} \mathrm{C}-\mathrm{N}$ bonds are due to chlorination.

${ }^{1}$ M. S. Dresselhaus, G. Dresselhaus, and P. C. Eklund, Science of Fullerenes and Carbon Nanotubes (Academic, San Diego, 1996).

${ }^{2}$ S. H. Lim, H. I. Elim, X. Y. Gao, A. T. S. Wee, W. Ji, J. Y. Lee, and J. Lin, Phys. Rev. B 73, 045402 (2006).

${ }^{3}$ K. N. Kudin, H. F. Bettinger, and G. E. Scuseria, Phys. Rev. B 63, 045413 (2001).

${ }^{4}$ E. T. Mickelson, I. W. Chiang, J. L. Zimmerman, P. J. Boul, J. Lozano, J. Liu, R. E. Smalley, R. H. Hauge, and J. L. Margrave, J. Phys. Chem. B 103, 4318 (1999).

${ }^{5}$ A. M. Rao, P. C. Eklund, S. Bandow, A. Thess, and R. E. Smalley, Nature (London) 388, 257 (1997).

${ }^{6}$ C. L. Yueh, J. C. Jan, J. W. Chiou, W. F. Pong, M.-H. Tsai, Y. K. Chang, Y. Y. Chen, Y. F. Lee, P. K. Tseng, S. L. Wei, C. Y. Wen, L. C. Chen, and K. H. Chen, Appl. Phys. Lett. 79, 3179 (2001).

${ }^{7}$ J. W. Chiou, C. L. Yueh, J. C. Jan, H. M. Tsai, W. F. Pong, I.-H. Hong, R. Klauser, M.-H. Tsai, Y. K. Chang, Y. Y. Chen, C. T. Wu, K. H. Chen, S. L. Wei, C. Y. Wen, L. C. Chen, and T. J. Chuang, Appl. Phys. Lett. 81, 4189 (2002).

${ }^{8}$ S. C. Ray, J. W. Chiou, W. F. Pong, and M.-H. Tsai, Crit. Rev. Solid State Mater. Sci. 31, 91 (2006).

${ }^{9}$ L. C. Chen, C. Y. Wen, C. H. Liang, W. K. Hong, K. J. Chen, H. C. Cheng, C. S. Shen, C. T. Wu, and K. H. Chen, Adv. Funct. Mater. 12, 687 (2002).

${ }^{10}$ S. Anders, J. Díaz, J. W. Ager III, R. Y. Lo, and D. B. Bogy, Appl. Phys. Lett. 71, 3367 (1997).

${ }^{11}$ S. Bhattacharyya, M. Lübbe, and F. Richter, J. Appl. Phys. 88, 5043 (2000).

${ }^{12}$ E. Unger, A. Graham, F. Kreupl, M. Liebau, and W. Hoenlein, Curr. Appl. Phys. 2, 107 (2002).

${ }^{13}$ M. Imamura, H. Shimada, N. Matsubayashi, M. Yumura, K. Uchida, S. Oshima, Y. Kuriki, Y. Yoshimura, T. Sato, and A. Nishijima, Jpn. J. Appl. Phys., Part 2 33, L1016, (1994).

${ }^{14}$ D. A. Fischer, R. M. Wentzcovitch, R. G. Carr, A. Continenza, and A. J. Freeman, Phys. Rev. B 44, 1427 (1991).

${ }^{15}$ M. C. Pyane, M. Teter, D. C. Allan, and J. D. Joannopoulos, Rev. Mod. Phys. 64, 1045 (1992).

${ }^{16}$ C.-W. Chen and M.-H. Lee, Nanotechnology 15, 480 (2004).

${ }^{17}$ I. Jimènez, W. M. Tong, D. K. Shuh, B. C. Holloway, M. A. Kelly, P. Pianetta, L. J. Terminello, and F. J. Himpsel, Appl. Phys. Lett. 74, 2620 (1999).

${ }^{18}$ H. Ago, T. Kugler, F. Cacialli, W. R. Salaneck, M. S. P. Shaffer, A. H. Windle, and R. H. Friend, J. Phys. Chem. B 103, 8116 (1999).

${ }^{19}$ S. Suzuki, Y. Watanabe, T. Kiyokura, K. G. Nath, T. Ogino, S. Heun, W. Zhu, C. Bower, and O. Zhou, Phys. Rev. B 63, 245418 (2001).

${ }^{20}$ S. C. Ray, C. W. Bao, H. M. Tsai, J. W. Chiou, J. C. Jan, K. P. Krishna Kumar, W. F. Pong, M.-H. Tsai, W.-J. Wang, C.-J. Hsu, T. I. T. Okpalugo, P. Papakonstantinou, and J. A. McLaughlin, Appl. Phys. Lett. 85, 4022 (2004).

${ }^{21}$ S. Bhattacharyya, C. Spaeth, and F. Richter, J. Appl. Phys. 89, 2414 (2001).

${ }^{22}$ G. Beamson and D. Briggs, High Resolution XPS of Organic Polymers (Wiley, New York, 1992). 